\title{
Melatonin and cortisol profiles in late midlife and their association with age-related changes in cognition
}

This article was published in the following Dove Press journal:

Nature and Science of Sleep

21 January 2016

Number of times this article has been viewed

\author{
Katja Linda Waller ${ }^{1,2}$ \\ Erik Lykke Mortensen ${ }^{2,3}$ \\ Kirsten Avlund ${ }^{2,3, \dagger}$ \\ Merete Osler ${ }^{3,4}$ \\ Birgitte Fagerlund ${ }^{5}$ \\ Martin Lauritzen ${ }^{2,6}$ \\ Steen Gammeltoft ${ }^{7}$ \\ Poul Jennum ${ }^{1,2}$
}

'Danish Center for Sleep Medicine, Clinic of Clinical Neurophysiology,

Rigshospitalet, University of

Copenhagen, Copenhagen, Denmark;

${ }^{2}$ Center for Healthy Aging, Faculty

of Health Sciences, University

of Copenhagen, Copenhagen,

Denmark; ${ }^{3}$ Department of Public

Health, University of Copenhagen,

Copenhagen, Denmark; ${ }^{4}$ Research

Center for Prevention and Health,

Rigshospitalet, Glostrup, Denmark;

${ }^{5}$ Center for Neuropsychiatric

Schizophrenia Research (CNSR),

Lundbeck Foundation Center

for Clinical Intervention and

Neuropsychiatric Schizophrenia

Research (CINS), Mental Health

Center Glostrup, Glostrup,

Denmark; ${ }^{6}$ Department of Clinical

Neurophysiology, Rigshospitalet,

Glostrup, Denmark; ${ }^{7}$ Department of

Clinical Biochemistry, Rigshospitalet,

Glostrup, Denmark

†Kirsten Avlund passed away on June 15,2012

Correspondence: Poul Jennum

Danish Center for Sleep Medicine,

Clinic of Clinical Neurophysiology,

Rigshospitalet, University of Copenhagen,

Nordre Ringvej 57, DK 2600 Glostrup,

Denmark

Tel +453863 25I2

Email poul.joergen.jennum@regionh.dk
Abstract: Previous studies have reported an association between circadian disturbances and age-related cognitive impairment. The aim was to study the 24-hour profiles of melatonin and cortisol in relation to cognitive function in middle-aged male subjects. Fifty healthy middle-aged males born in 1953 were recruited from a population-based cohort based on previous cognitive assessments in young adulthood and late midlife. The sample included 24 cognitively high-functioning and 26 cognitively impaired participants. Saliva samples were collected every 4 hours over a 24-hour period and analyzed for cortisol and melatonin levels by immunoassay. All participants exhibited clear circadian rhythms of salivary melatonin and cortisol. Salivary melatonin concentrations had a nocturnal peak at approximately $4 \mathrm{am}$. The median nocturnal melatonin response at 4 am was significantly lower in the cognitively impaired group than in the high-functioning group $(-4.6 \mathrm{pg} / \mathrm{mL}, 95 \% \mathrm{CI}:-7.84,-1.36, P=0.006)$. The 24-hour mean melatonin concentration (high-functioning group: $4.80 \pm 0.70 \mathrm{pg} / \mathrm{mL}$, vs cognitively impaired group: $4.81 \pm 0.76 \mathrm{pg} / \mathrm{mL} ; P>0.05$ ) (or the area under the curve, AUC) was not significantly different between the two groups. Cortisol levels were low during the night, and peaked at approximately $8 \mathrm{am}$. Median cortisol concentrations were similar at all times, as were the 24-hour mean cortisol concentrations and AUC. To the best of our knowledge, ours is the first study to assess circadian measures (ie, melatonin and cortisol) in healthy middle-aged men with different cognitive trajectories in midlife. We found evidence of altered circadian rhythms with a reduced nocturnal melatonin response at 4 am in men with cognitive impairment. The 24-hour concentration and AUC of melatonin and cortisol were similar in the cognitively high-functioning group and in the cognitively impaired.

Keywords: diurnal variation, middle-aged males, minimal cognitive impairment

\section{Introduction}

Aging is associated with disrupted sleep and circadian rhythm, and increased prevalence of cognitive impairment. Growing evidence suggests that normal aging is associated with a dysfunction of the suprachiasmatic nucleus ( $\mathrm{SCN})$ in the hypothalamus, and that this is even more pronounced in brain pathologies. The mechanisms underlying disrupted circadian rhythm may include age-related or pathological degeneration of the retina-SCN-pineal axis and their neuronal connections..$^{1-3}$

Melatonin is the main hormone synthesized by the pineal gland and is controlled by the SCN. Its rhythm in saliva, plasma, or its major metabolite, 6-sulfatoxymelatonin (aMT6s), in urine provides the best available index of the timing of the internal circadian clock in humans. ${ }^{4}$ Melatonin has a typical circadian pattern of low levels during the daytime, while the highest levels are released at night. ${ }^{2,4}$ Cortisol secretion is coordinated by the hippocampus and the hypothalamic-pituitary-adrenal (HPA) axis. 
It has a well-defined diurnal pattern, reaching its peak in the morning and declining thereafter, reaching a minimum level at approximately midnight. ${ }^{5}$

With few exceptions, ${ }^{6,7}$ studies have reported a decline in the amount and amplitude of melatonin, or an advance in the timing of melatonin rhythm with aging, ${ }^{8-11}$ and considerable interindividual variability at all ages. ${ }^{10,12}$ Several neurodegenerative conditions, particularly Alzheimer Disease (AD) and Parkinson Disease (PD), are characterized by more irregular circadian rhythms and lower melatonin content than in agematched controls. ${ }^{13-21}$ Melatonin levels in cerebrospinal fluid (CSF) and in the postmortem human pineal gland are already reduced in preclinical $\mathrm{AD}$ subjects, who are still cognitively intact. ${ }^{17,18}$ Furthermore, melatonin levels are related to age and the severity of cognitive impairment, ${ }^{15,22}$ and decrease with the progression of a dementia disease. ${ }^{18}$ With respect to cortisol, a significant increase in nocturnal levels and a clearly flattened circadian profile have been observed in the elderly, this being even more pronounced in demented subjects. ${ }^{15,16}$ Whether these relationships are causal or merely a marker of the neurodegenerative process has not been determined.

Recently, it has been reported that salivary melatonin rhythm is significantly phase-advanced in individuals with mild cognitive impairment (MCI) relative to age-matched controls, ${ }^{23}$ and so is consistent with changes observed in AD. Moreover, impairment of the circadian rhythm noted in wrist actigraphy studies has been found to be associated with an increased risk of developing MCI or dementia in cognitively intact subjects. ${ }^{24,25}$

Even though disturbed circadian rhythm and altered hormonal secretion may play a role in the aging process, and may serve as an early sign of the development of agerelated brain pathologies, remarkably little is known about the associations of cognitive changes over time with circadian rhythms in the elderly.

For the first time, a study has sought to examine the longitudinal association between cognition and circadian rhythm and to assess salivary melatonin and cortisol concentrations over 24 hours in healthy middle-aged men. We hypothesized that participants with early subclinical cognitive decline would show more disrupted circadian rhythms and alterations in the diurnal melatonin and cortisol concentrations than subjects with preserved cognition.

\section{Methods}

\section{Subjects}

The present study was based on a subpopulation of 50 middleaged Danish males, who participated in the larger Center for
Healthy Aging Clinical Neuroscience project. For this study, we included only those participants who completed saliva collection between December 2010 and December 2011. All participants were recruited from the Metropolit cohort, comprising 11,532 males born in 1953 in the Copenhagen Metropolitan area. The whole sample was selected from the 1985 members of the Metropolit cohort who participated in a follow-up study in 2009-2011 as part of the establishment of the Copenhagen Aging and Midlife Biobank (CAMB). ${ }^{26}$ A more detailed description of the original Metropolit cohort has been presented elsewhere. ${ }^{27}$ Only data relevant to the present study are described here.

Draft board intelligence scores had previously been collected for members of the Metropolit Cohort. ${ }^{27,28}$ The draft intelligence test is the Børge Priens Prøve (BPP), which has a correlation coefficient of 0.82 with the Wechsler Intelligence Scale. ${ }^{29}$ Three subtests of the Intelligent Structure Test (I-S-T 2000R $)^{26}$ were administered as part of the CAMB midlife data collection, and a regression model was developed to predict the expected level of midlife cognitive performance from the draft board intelligence scores. Based on the residuals from this regression model, we identified 249 individuals who performed substantially better (standardized residuals from the regression model ranging from 2.80 to 0.96 ) and 302 individuals who performed substantially worse (standardized residuals ranging from -3.20 to -0.99 ) on the midlife cognitive test than expected from their military draft board intelligence score. Of the 551 potential participants, 37 were excluded for various reasons (including 3 potential participants who died during the study period), and the remaining 514 individuals were invited to participate in a clinical follow-up study. Among those with substantially better than expected midlife cognitive scores, $41.0 \%$ (102 individuals) participated, while 34.8\% (105 individuals) of those with substantially worse than expected cognitive scores participated in the clinical study.

In summary, between 2010 and 2012, we invited a total of 551 subjects to take part in the multidisciplinary Center for Healthy Aging Clinical Neuroscience project. In addition to saliva sampling, the participants underwent studies of sleep, cognition, MRI, and dental health. Data were collected for the whole cohort, although for the purpose of the current study, we used only saliva samples collected within the first year of the study. Of the 60 subjects whose salivary levels were assayed, only those with a complete data set containing both melatonin and cortisol were included. We also excluded participants from the analysis if two or more saliva samples were missing. The final sample of males completing the saliva 
samples included 26 and 24 subjects classified as cognitively impaired and cognitively high-functioning, respectively. Exclusion criteria were known neurological or psychiatric disorders, major depressive illness (within the past 10 years), and alcohol or drug abuse.

All subjects underwent a structured clinical interview to ascertain sociodemographic characteristics, and medical and family histories, and standard laboratory blood tests. A physical examination included measurements of blood pressure, waist, weight, and height. In order to examine the possible effect of depressive symptoms on cortisol and melatonin evaluation, the Beck Depression Inventory (BDI) was used to assess depressive symptoms. After recruitment, written and verbal information was given about the procedures. All subjects gave their written informed consent to participate. The study design was approved by the ethics committee of the Capital Region of Denmark.

\section{Saliva sampling}

Melatonin and cortisol secretion in the saliva of each participant was assessed. Participants collected the saliva samples themselves, while at home, on the day after the overnight sleep study. Saliva samples were collected on seven occasions, every 4 hours for 24 hours (from noon to noon). Participants were encouraged to maintain their regular sleep habits, but were asked to wake up before each of the night-time sampling sessions and to keep the lighting $\operatorname{dim}(<30$ lux $)$ during the collection. Subjects were given written and oral instructions before saliva collection. They were asked not to drink or eat for at least 60 minutes before saliva collection, to refrain from smoking for at least 30 minutes and to rinse their mouths with water before collecting saliva. Samples were sent to the laboratory by mail or were delivered in person. Seven subjects missed more than one of the seven scheduled sampling times and were excluded from the analysis. Data from 50 participants were included in the present study.

\section{Salivary melatonin and cortisol analysis}

Salivary cortisol levels were analyzed by competitive immunoassay (Salimetrics Europe Ltd, Newmarket, Suffolk, UK). Intra-assay precision (within-run) was taken to be the mean coefficient of variation (CV), which had a value of 3.4\%; interassay precision (run-to-run) was calculated as the mean $\mathrm{CV}$, and had a value of 5.1\%. Salivary melatonin levels were analyzed by the Direct Saliva Melatonin Radio Immunoassay (Bühlmann Laboratories AG, Schönenbuch, Switzerland). The intra-assay precision (mean $\mathrm{CV}$ ) was $5.2 \%$, and the interassay precision (mean CV) was $10.2 \%$.

\section{Statistics}

Median regression - a nonparametric alternative to ordinary least squares regression - was used to identify group median differences in diurnal melatonin and cortisol concentrations. Figures 1 and 2 are based on these models, with error bars derived from the median absolute deviations. Group comparisons for sociodemographic and clinical data were carried out using independent samples $t$-tests (continuous variables) or $\chi^{2}$ tests (categorical variables). All analyses were done using Stata 13.1 (StataCorp, College Station, TX, USA).

\section{Results \\ Sociodemographic and clinical characteristics}

The sociodemographic and clinical characteristics of the two groups are presented in Table 1 . The only significant differences between the groups were with respect to educational status, whereby members of the cognitively high-functioning group tended to have a higher educational level than the cognitively impaired individuals $(P=0.03)$.

\section{Melatonin and cortisol}

All 50 participants showed clear circadian rhythms of salivary melatonin and cortisol. The diurnal melatonin concentrations for the two groups are shown in Figure 1. Daytime melatonin levels were low and significantly higher during the night (Figure 1). The median nocturnal melatonin response at 4 am was significantly lower in the cognitively impaired group than in the cognitively high-functioning group (-4.6 pg/mL, 95\% CI: $-7.84,-1.36, P=0.006)$. At all other times, the median difference between the two groups was not statistically significant. The area under the curve

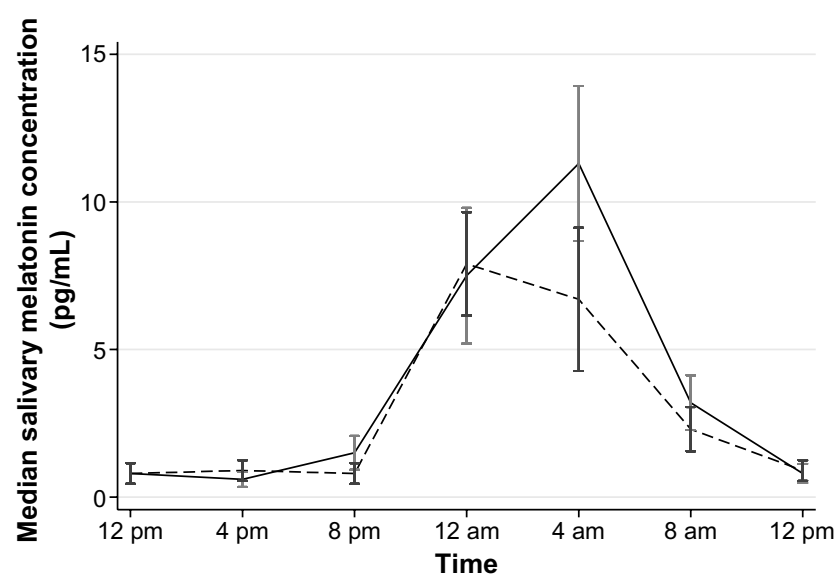

Figure I Median circadian profile of salivary melatonin in cognitively impaired (dashed line) and cognitively high-functioning (solid line) participants.

Note: Values are expressed as median \pm median absolute deviation. 


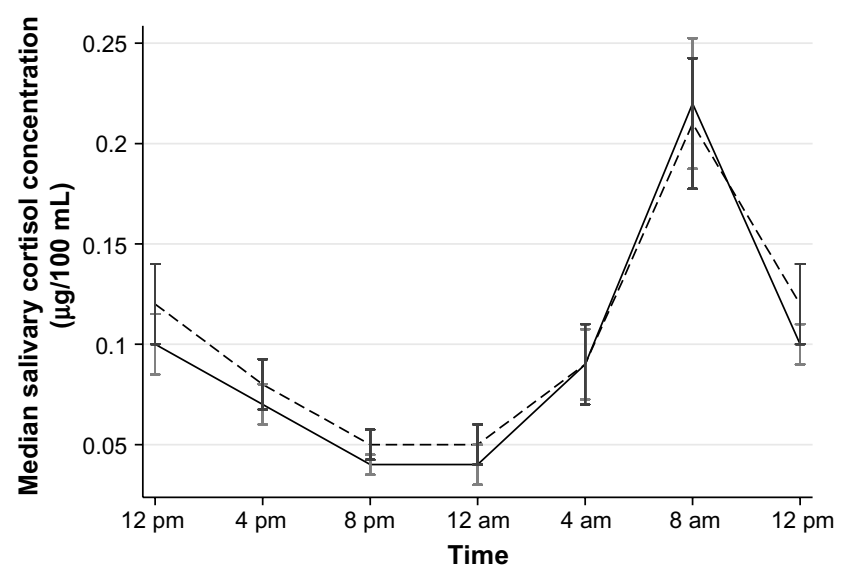

Figure 2 Median circadian profile of salivary cortisol in cognitively impaired (dashed line) and cognitively high-functioning (solid line) participants.

Note: Values are expressed as median \pm median absolute deviation.

(AUC) and mean 24-hour melatonin concentration were similar in the two groups (Table 2).

All participants had a nocturnal melatonin peak at midnight, 4 am, or 8 am (Table 3). The distribution of peak times appears to be phase-advanced toward earlier times for the cognitively impaired group compared with the high-functioning group, but this pattern was not statistically significant $\left(\chi^{2}=2.99, P=0.22\right)$. There was considerable interindividual variation within both groups in the total amount of melatonin secreted and the nocturnal peak values, ranging from 3.8 to $119 \mathrm{pg} / \mathrm{mL}$, and 1 to $84 \mathrm{pg} / \mathrm{mL}$, respectively.

The median diurnal cortisol concentrations for the two groups are shown in Figure 2. In both groups, the cortisol levels were low overnight, and peaked at approximately $8 \mathrm{am}$. At all times, the median difference between the groups was statistically nonsignificant. The AUC and 24-hour mean cortisol concentration were similar in the two groups (Table 2).

\section{Discussion}

The present study found no differences between groups with respect to the peak levels or absolute amounts of melatonin and cortisol secreted over a 24-hour period. However, we observed that the nocturnal melatonin response at 4 am was significantly lower in the cognitively impaired group than in the cognitively high-functioning males, indicating an alteration in their melatonin secretion rhythm.

We also found clear circadian rhythms of salivary melatonin and cortisol in all participants, although the distribution of mean hormone concentrations and nocturnal peak levels varied considerably between individuals.

Age-related changes in the circadian time-keeping system, including phase advancement in sleep and circadian
Table I Distribution of sociodemographic and clinical variables in 50 cognitively high-functioning (group I) and cognitively impaired (group 2) middle-aged men

\begin{tabular}{|c|c|c|c|}
\hline & $\begin{array}{l}\text { Group I } \\
(\mathrm{N}=24)\end{array}$ & $\begin{array}{l}\text { Group } 2 \\
(\mathrm{~N}=26)\end{array}$ & $P$-value \\
\hline Age (years) & $57.5 \pm 0.45$ & $57.3 \pm 0.45$ & ns \\
\hline Sex $(\%$ male $)$ & 100 & 100 & ns \\
\hline Ethnicity (\% Caucasian) & 100 & 100 & ns \\
\hline Years in education & $13.96 \pm 2.46$ & $12.5 \pm 2.12$ & 0.03 \\
\hline BMI $\left(\mathrm{kg} / \mathrm{m}^{2}\right)$ & $27.1 \pm 4.45$ & $27.06 \pm 3.71$ & ns \\
\hline Waist circumference $(\mathrm{cm})$ & $95.78 \pm 25$ & $96.38 \pm 26.5$ & ns \\
\hline \multicolumn{4}{|l|}{ Blood pressure } \\
\hline Systolic & $148 \pm 14$ & $137 \pm 32$ & ns \\
\hline Diastolic & $89 \pm 8$ & $83 \pm 24$ & ns \\
\hline \multicolumn{4}{|l|}{ Alcohol drinking habit } \\
\hline Current (yes/no) & $23 / 1$ & $25 / 1$ & ns \\
\hline \multicolumn{4}{|l|}{ Smoking habit, n (\%) } \\
\hline Current & $9(4 I)$ & II (42) & ns \\
\hline Former & $8(29)$ & $6(23)$ & ns \\
\hline Never & $7(30)$ & $9(35)$ & ns \\
\hline BDI-II & $2.48 \pm 3.24$ & $3.32 \pm 4.31$ & ns \\
\hline ESS & $6.40 \pm 3.42$ & $4.20 \pm 2.61$ & ns \\
\hline \multicolumn{4}{|c|}{ Physical and psychiatric morbidity, n (\%) } \\
\hline Hypercholesterolemia & $8(2)$ & $3(4)$ & ns \\
\hline Hypertension & $21(5)$ & $19(5)$ & ns \\
\hline $\begin{array}{l}\text { Other current or former } \\
\text { cardiovascular disease }\end{array}$ & $0(0)$ & $15(4)$ & ns \\
\hline Type 2 diabetes & $0.5(\mathrm{I})$ & $0(0)$ & ns \\
\hline Asthma/COPD & $I(I)$ & $2(3)$ & ns \\
\hline Arthritis & $12(3)$ & $27(7)$ & ns \\
\hline Allergic illness & $4(4)$ & $\mathrm{I}(\mathrm{I})$ & ns \\
\hline $\begin{array}{l}\text { Any current or former } \\
\text { migraine or other } \\
\text { neurological disease }\end{array}$ & $18(17)$ & $11(10)$ & ns \\
\hline Any former malignity & 0 & $0.5(I)$ & ns \\
\hline Any former depressive episode & $2(8)$ & $12(3)$ & ns \\
\hline
\end{tabular}

Notes: Data are mean \pm standard error of the mean, or number and percentage. $P$-values are those from independent-samples $t$-tests (continuous variables) or $\chi^{2}$ tests (categorical variables). $P$-values $\geq 0.05$ were considered not significant.

Abbreviations: ns, not significant; BMI, body mass index; BDI-II, Beck Depression Inventory; ESS, Epworth Sleepiness Scale.

rhythm and decreased amplitude of melatonin secretion have often been described. ${ }^{8,9,11,30,31}$

Although a decline in melatonin production is considered a hallmark of aging, beginning between 20 and 30 years of age, ${ }^{32}$ early in midlife, ${ }^{8}$ or even later, ${ }^{33}$ there is considerable interindividual variation in excretion rates at all age $\mathrm{s}^{10,12}$ as well as differences between the sexes. ${ }^{7}$ Our results confirmed the common finding that melatonin levels vary greatly between individuals, which has been ascribed mainly to genetic influences on the levels of melatonin secretion. ${ }^{12}$

Disrupted circadian rhythm and reduced melatonin secretion, which exceed those observed during normal aging, have been extensively reported in neurodegenerative disorders, and especially in $\mathrm{AD} .{ }^{1,14-20,22,31,34}$ The melatonin rhythm is 
Table 2 The circadian parameters of salivary melatonin and cortisol in 24 cognitively high-functioning (group I) and 26 cognitively impaired (group 2) middle-aged men

\begin{tabular}{|c|c|c|c|}
\hline & $\begin{array}{l}\text { Group I } \\
(\mathrm{N}=24), \\
\text { estimate } \pm \mathrm{SE}\end{array}$ & $\begin{array}{l}\text { Group } 2 \\
(\mathrm{~N}=26), \\
\text { estimate } \pm \mathrm{SE}\end{array}$ & $P$-value* \\
\hline $\begin{array}{l}\text { Median peak melatonin } \\
\text { level }(\mathrm{pg} / \mathrm{mL}) \text { at } 4 \mathrm{am}\end{array}$ & $10.50 \pm 1.19$ & $5.90 \pm 1.14$ & 0.006 \\
\hline $\begin{array}{l}\text { Mean 24-hour mean } \\
\text { melatonin level }(\mathrm{pg} / \mathrm{mL})\end{array}$ & $4.80 \pm 0.70$ & $4.8 \mathrm{I} \pm 0.76$ & ns \\
\hline $\begin{array}{l}\text { Mean AUC melatonin } \\
(\mathrm{h} \times \mu \mathrm{g} / \mathrm{mL})\end{array}$ & $126.7 \pm 6.6$ & $127.5 \pm 7.7$ & ns \\
\hline $\begin{array}{l}\text { Median peak level cortisol } \\
(\mu g / 100 \mathrm{~mL}) \text { at } 8 \mathrm{am}\end{array}$ & $0.16 \pm 0.03$ & $0.12 \pm 0.02$ & ns \\
\hline $\begin{array}{l}\text { Mean 24-hour mean } \\
\text { cortisol level }(\mu \mathrm{g} / 100 \mathrm{~mL})\end{array}$ & $0.1 I \pm 0.0 I$ & $0.12 \pm 0.01$ & ns \\
\hline $\begin{array}{l}\text { Mean AUC cortisol } \\
(\mathrm{h} \times \mu \mathrm{g} / 100 \mathrm{~mL})\end{array}$ & $2.70 \pm 0.07$ & $2.73 \pm 0.08$ & ns \\
\hline
\end{tabular}

practically abolished in many individuals afflicted with dementia disorders.

A deterioration of the circadian time-keeping system can arise from various causes, including degeneration of the $\mathrm{SCN}$, changes in the pineal gland and its neuronal transmissions/ projections, reduced expression and density of melatonin receptors, and changes in the light input pathways toward the SCN. ${ }^{17,31}$

Moreover, changes in behavior affecting light exposure and social zeitgebers are common in the elderly, especially in demented individuals..$^{21,31}$

Dysfunction of the circadian system has been linked to compromised control of metabolism, reactive oxygen species homeostasis, antioxidant defense, DNA repair, and autophagy. This, in turn, may contribute to brain aging and neurodegeneration, thus increasing the likelihood of developing age-associated brain pathologies. ${ }^{3,35}$ In this study, we found a significantly impaired melatonin response at 4 am and a tendency toward

Table 3 Distribution of melatonin nocturnal peak times in cognitively impaired and cognitively high-functioning participants

\begin{tabular}{llllll}
\hline Group & \multicolumn{4}{l}{ Melatonin nocturnal peak time } & Total \\
\cline { 2 - 4 } & $\mathbf{1 2}$ am & $\mathbf{4}$ am & $\mathbf{8}$ am & subjects (N) \\
\hline $\begin{array}{l}\text { Cognitively } \\
\text { impaired (n) }\end{array}$ & II & II & 4 & 26 \\
$\begin{array}{l}\text { Cognitively } \\
\text { high-functioning (n) }\end{array}$ & 6 & 16 & 2 & 24 \\
\hline
\end{tabular}

Note: The distribution of peak times appears to be phase-advanced toward earlier times for the cognitively impaired group relative to the cognitively high-functioning group, but this pattern was not statistically significant $\left(\chi^{2}=2.99, P=0.22\right)$. phase advancement in the cognitively impaired subjects relative to the high-functioning subjects. The finding of normal levels of melatonin is consistent with those of other studies, showing that melatonin deficiency is correlated with the severity of cognitive impairment and is aggravated by the advance of Alzheimer, ${ }^{15,16,18}$ Parkinson, ${ }^{14,36}$ and Huntington ${ }^{19}$ diseases.

Recently, it has been reported that salivary melatonin secretion onset is significantly phase-advanced in individuals with $\mathrm{MCI}$, and even related to poorer memory performance than age-matched controls. ${ }^{23}$ Thus, our results are in line with previous research suggesting that patients with $\mathrm{MCI}$ may have normal melatonin synthesis, but alterations in the timing of its release. ${ }^{23}$

Our findings support the idea of a link between those neuronal processes that affect cognitive aging, and those leading to alterations in melatonin secretion. Although the group difference was significant, it was relatively small and should be interpreted with caution. Our data do not allow us to establish causality, and the underlying mechanism linking alterations in the timing of melatonin secretion with cognitive aging is yet to be clearly determined.

To the best of our knowledge, no other studies have examined the association between slight changes in cognition and circadian rhythms of melatonin and cortisol in healthy middle-aged males. Our study has some strengths. First, it involves a subpopulation of middle-aged males drawn from a well-established, population-based birth cohort that has been extensively screened for neurological and psychiatric comorbidities. Second, it uses saliva sampling, which is a practical, reliable, and noninvasive method for measuring circadian rhythmicity.

However, our results should be interpreted in the context of the study's limitations. First, we examined a relatively small sample of individuals. Second, the results may be generalized to middle-aged and elderly males who are in good physical and mental health, but not to other age groups, women, cognitively impaired clinical samples, or more ethnically diverse populations. Third, more frequent sampling is required to assess the melatonin and cortisol rhythm comprehensively. Finally, the study did not examine other circadian rhythm parameters, such as achrophase, onset and offset time, duration of hormone secretion, and daytime levels. Further research, with longitudinal designs and larger populations, is needed to confirm the results observed in the present study and to identify the underlying mechanisms.

In conclusion, our results suggest that melatonin altered circadian rhythms with a reduced nocturnal melatonin response rather than the absolute amount of diurnal melatonin and 
cortisol that could serve as a marker of subtle cognitive changes. Age-specific data about salivary melatonin and cortisol levels in middle-aged males were obtained that establish an important baseline for further studies into the link between circadian rhythms, sleep, and cognition in the aging process.

\section{Acknowledgment}

This study was supported by an unrestricted grant from the Nordea Foundation, Denmark.

\section{Author contributions}

Katja Linda Waller: study conception and design, acquisition of data, statistical analysis, interpretation of data, and drafting of manuscript; main author. Martin Lauritzen and Poul Jennum: study conception and design, acquisition of data, critical revision of manuscript. Erik Lykke Mortensen: study conception and design, acquisition of data, critical revision of the manuscript. Steen Gammeltoft: analysis of salivary cortisol and melatonin levels and critical revision of the manuscript. Kirsten Avlund, Merete Osler, and Birgitte Fagerlund: study conception and design, acquisition of data and critical revision of the manuscript. Our coauthor, Kirsten Avlund, died on September 1, 2013. She made a significant contribution to this paper (including data analysis and critical revision of the manuscript), and was fully aware of its content before her death. The authors gave final approval of the version to be published, and agree to be accountable for all aspects of the work.

\section{Disclosure}

The authors report no conflicts of interest in this work.

\section{References}

1. Skene DJ, Vivien-Roels B, Sparks DL, et al. Daily variation in the concentration of melatonin and 5-methoxytryptophol in the human pineal gland: effect of age and Alzheimer's disease. Brain Res. 1990;528: $170-174$.

2. Hardeland R. Melatonin in aging and disease - multiple consequences of reduced secretion, options and limits of treatment. Aging Dis. 2012;3:194-225.

3. Kondratova AA, Kondratov RV. The circadian clock and pathology of the ageing brain. Nat Rev Neurosci. 2012;13:325-335.

4. Arendt J. Melatonin and human rhythms. Chronobiol Int. 2006;23: 21-37.

5. Fries E, Dettenborn L, Kirschbaum C. The cortisol awakening response (CAR): facts and future directions. Int J Psychophysiol. 2009;72: $67-73$.

6. Fourtillan JB, Brisson AM, Fourtillan M, Ingrand I, Decourt JP, Girault J. Melatonin secretion occurs at a constant rate in both young and older men and women. Am J Physiol Endocrinol Metab. 2001;280: E11-E22.

7. Kin NM, Nair NP, Schwartz G, Thavundayil JX, Annable L. Secretion of melatonin in healthy elderly subjects: a longitudinal study. Ann NY Acad Sci. 2004;1019:326-329.
8. Zhou JN, Liu RY, van HJ, Hofman MA, Swaab DF. Alterations in the circadian rhythm of salivary melatonin begin during middle-age. J Pineal Res. 2003;34:11-16.

9. Ohashi Y, Okamoto N, Uchida K, Iyo M, Mori N, Morita Y. Differential pattern of the circadian rhythm of serum melatonin in young and elderly healthy subjects. Biol Signals. 1997;6:301-306.

10. Wetterberg L, Bergiannaki JD, Paparrigopoulos T, et al. Normative melatonin excretion: a multinational study. Psychoneuroendocrinology. 1999;24:209-226.

11. Duffy JF, Zeitzer JM, Rimmer DW, Klerman EB, Dijk DJ, Czeisler CA. Peak of circadian melatonin rhythm occurs later within the sleep of older subjects. Am J Physiol Endocrinol Metab. 2002;282:E297-E303.

12. Burgess HJ, Fogg LF. Individual differences in the amount and timing of salivary melatonin secretion. PLoS One. 2008;3:e3055.

13. Breen DP, Vuono R, Nawarathna U, et al. Sleep and circadian rhythm regulation in early Parkinson disease. JAMA Neurol. 2014;71:589-595

14. Videnovic A, Noble C, Reid KJ, et al. Circadian melatonin rhythm and excessive daytime sleepiness in Parkinson disease. JAMA Neurol. 2014;71:463-469.

15. Magri F, Locatelli M, Balza G, et al. Changes in endocrine circadian rhythms as markers of physiological and pathological brain aging. Chronobiol Int. 1997;14:385-396.

16. Ferrari E, Arcaini A, Gornati R, et al. Pineal and pituitary-adrenocortical function in physiological aging and in senile dementia. Exp Gerontol. 2000;35:1239-1250.

17. Wu YH, Swaab DF. The human pineal gland and melatonin in aging and Alzheimer's disease. J Pineal Res. 2005;38:145-152.

18. Zhou JN, Liu RY, Kamphorst W, Hofman MA, Swaab DF. Early neuropathological Alzheimer's changes in aged individuals are accompanied by decreased cerebrospinal fluid melatonin levels. J Pineal Res. 2003;35:125-130

19. Aziz NA, Pijl H, Frolich M, et al. Delayed onset of the diurnal melatonin rise in patients with Huntington's disease. J Neurol. 2009;256:1961-1965.

20. Uchida K, Okamoto N, Ohara K, Morita Y. Daily rhythm of serum melatonin in patients with dementia of the degenerate type. Brain Res. 1996;717:154-159.

21. Mishima K, Tozawa T, Satoh K, Matsumoto Y, Hishikawa Y, Okawa M. Melatonin secretion rhythm disorders in patients with senile dementia of Alzheimer's type with disturbed sleep-waking. Biol Psychiatry. 1999;45:417-421

22. Ferrari E, Magri F. Role of neuroendocrine pathways in cognitive decline during aging. Ageing Res Rev. 2008;7:225-233.

23. Naismith SL, Hickie IB, Terpening Z, et al. Circadian misalignment and sleep disruption in mild cognitive impairment. J Alzheimers Dis. 2014;38:857-866

24. Tranah GJ, Blackwell T, Stone KL, et al. Circadian activity rhythms and risk of incident dementia and mild cognitive impairment in older women. Ann Neurol. 2011;70:722-732.

25. Schlosser Covell GE, Dhawan PS, Lee Iannotti JK, et al. Disrupted daytime activity and altered sleep-wake patterns may predict transition to mild cognitive impairment or dementia: a critically appraised topic. Neurologist. 2012;18:426-429.

26. Avlund K, Osler M, Mortensen EL, et al. Copenhagen Aging and Midlife Biobank (CAMB): an introduction. J Aging Health. 2014;26:5-20.

27. Osler M, Lund R, Kriegbaum M, Christensen U, Andersen AM. Cohort profile: the Metropolit 1953 Danish male birth cohort. Int J Epidemiol. 2006;35:541-545.

28. Osler M, Avlund K, Mortensen EL. Socio-economic position early in life, cognitive development and cognitive change from young adulthood to middle age. Eur J Public Health. 2013;23:974-980.

29. Mortensen EL, Reinisch RJ, Teasdale TW. Intelligence as measured by the WAIS and a military draft board group test. Scand J Psychol. 1989;30:315-318.

30. Monk TH. Aging human circadian rhythms: conventional wisdom may not always be right. J Biol Rhythms. 2005;20:366-374. 
31. Skene DJ, Swaab DF. Melatonin rhythmicity: effect of age and Alzheimer's disease. Exp Gerontol. 2003;38:199-206.

32. Kennaway DJ, Lushington K, Dawson D, Lack L, van den Heuvel C, Rogers N. Urinary 6-sulfatoxymelatonin excretion and aging: new results and a critical review of the literature. $J$ Pineal Res. 1999;27:210-220.

33. Zhao ZY, Xie Y, Fu YR, Bogdan A, Touitou Y. Aging and the circadian rhythm of melatonin: a cross-sectional study of Chinese subjects 30-110 yr of age. Chronobiol Int. 2002;19:1171-1182.

34. Liu RY, Zhou JN, van HJ, Hofman MA, Swaab DF. Decreased melatonin levels in postmortem cerebrospinal fluid in relation to aging, Alzheimer's disease, and apolipoprotein E-epsilon4/4 genotype. J Clin Endocrinol Metab. 1999;84:323-327.
35. Sarlak G, Jenwitheesuk A, Chetsawang B, Govitrapong P. Effects of melatonin on nervous system aging: neurogenesis and neurodegeneration. J Pharmacol Sci. 2013;123:9-24.

36. Bordet R, Devos D, Brique S, et al. Study of circadian melatonin secretion pattern at different stages of Parkinson's disease. Clin Neuropharmacol. 2003;26:65-72.

\section{Publish your work in this journal}

Nature and Science of Sleep is an international, peer-reviewed, open access journal covering all aspects of sleep science and sleep medicine, including the neurophysiology and functions of sleep, the genetics of sleep, sleep and society, biological rhythms, dreaming, sleep disorders and therapy, and strategies to optimize healthy sleep. The journal welcomes

\section{Dovepress}

original research, clinical \& epidemiological studies, reviews \& evaluations, case reports and extended reports. The manuscript management system is completely online and includes a very quick and fair peerreview system, which is all easy to use. Visit http://www.dovepress.com/ testimonials.php to read real quotes from published authors.

Submit your manuscript here: http://www.dovepress.com/nature-and-science-of-sleep-journal 